\title{
Tight junctions and the modulation of barrier function in disease
}

\author{
Carola Förster
}

Accepted: 18 March 2008 / Published online: 16 April 2008

(C) Springer-Verlag 2008

\begin{abstract}
Tight junctions create a paracellular barrier in epithelial and endothelial cells protecting them from the external environment. Two different classes of integral membrane proteins constitute the tight junction strands in epithelial cells and endothelial cells, occludin and members of the claudin protein family. In addition, cytoplasmic scaffolding molecules associated with these junctions regulate diverse physiological processes like proliferation, cell polarity and regulated diffusion. In many diseases, disruption of this regulated barrier occurs. This review will briefly describe the molecular composition of the tight junctions and then present evidence of the link between tight junction dysfunction and disease.
\end{abstract}

Keywords Tight junction - Occludin - Claudin · Cancer . Inflammation · Toxin · Hereditary · Vascular

\section{Introduction}

Tight junctions (TJ) (zonulae occludentes) form a continuous, circumferential, beltlike structure at the boundary between the apical and the basolateral membrane domains in epithelial and endothelial cells. By constituting a regulated diffusion barrier for the paracellular pathway, TJs establish separate compartments in multicellular organisms and are also crucial for the exchange of substances between the internal and external cellular environment by the expression of tissue-specific transport proteins and chan-

C. Förster $(\square)$

Institute of Anatomy and Cell Biology,

University of Würzburg, Koellikerstrasse 6,

97070 Würzburg, Germany

e-mail: carola.foerster@mail.uni-wuerzburg.de nels. The transmembrane proteins constituting the TJs are attached to the cytoskeleton, thereby linking cell-cell and cell-substratum adhesion sites. In addition, cytoplasmic plaque proteins constitute scaffolds for TJ assembly or are involved in the regulation of processes like transcription, proliferation and differentiation into a tissue-specific regulated diffusion barrier in physiology and development. Many excellent reviews have summarised data regarding the molecular composition and function of TJs (Ebnet 2008; Gonzalez-Mariscal et al. 2003; Matter and Balda 2003a; Mitic and Anderson 1998; Schneeberger and Lynch 2004; Tsukita and Furuse 1999; Zahraoui et al. 2000), so that the scope of the current review is focused on disturbances of TJ function in human diseases.

\section{Structure of the tight junction}

As the apicalmost part of the junctional complex (Farquhar and Palade 1963), the TJ forms a continuous, circumferential belt separating apical and basolateral plasma membrane domains, working as a barrier within the intercellular space and as a fence within the plasma membrane. In recent years, information on the molecular composition of TJs, in particular their transmembrane molecules, has accumulated, forming the basis of our current understanding of the structure and function of TJs in molecular terms (Fig. 1). The morphology of TJs has been intensively analysed by freeze-fracture electron microscopy (Staehelin 1973; Wolburg et al. 2003), where they appear as a set of continuous, anastomosing transmembraneous particle strands on the inner leaflet of the plasma membrane (P-face) with complementary vacant grooves on the outer leaflet (E-face) (Fig. 2). The number and complexity of ramification of the network of TJ strands depends on the cell type, in sum 


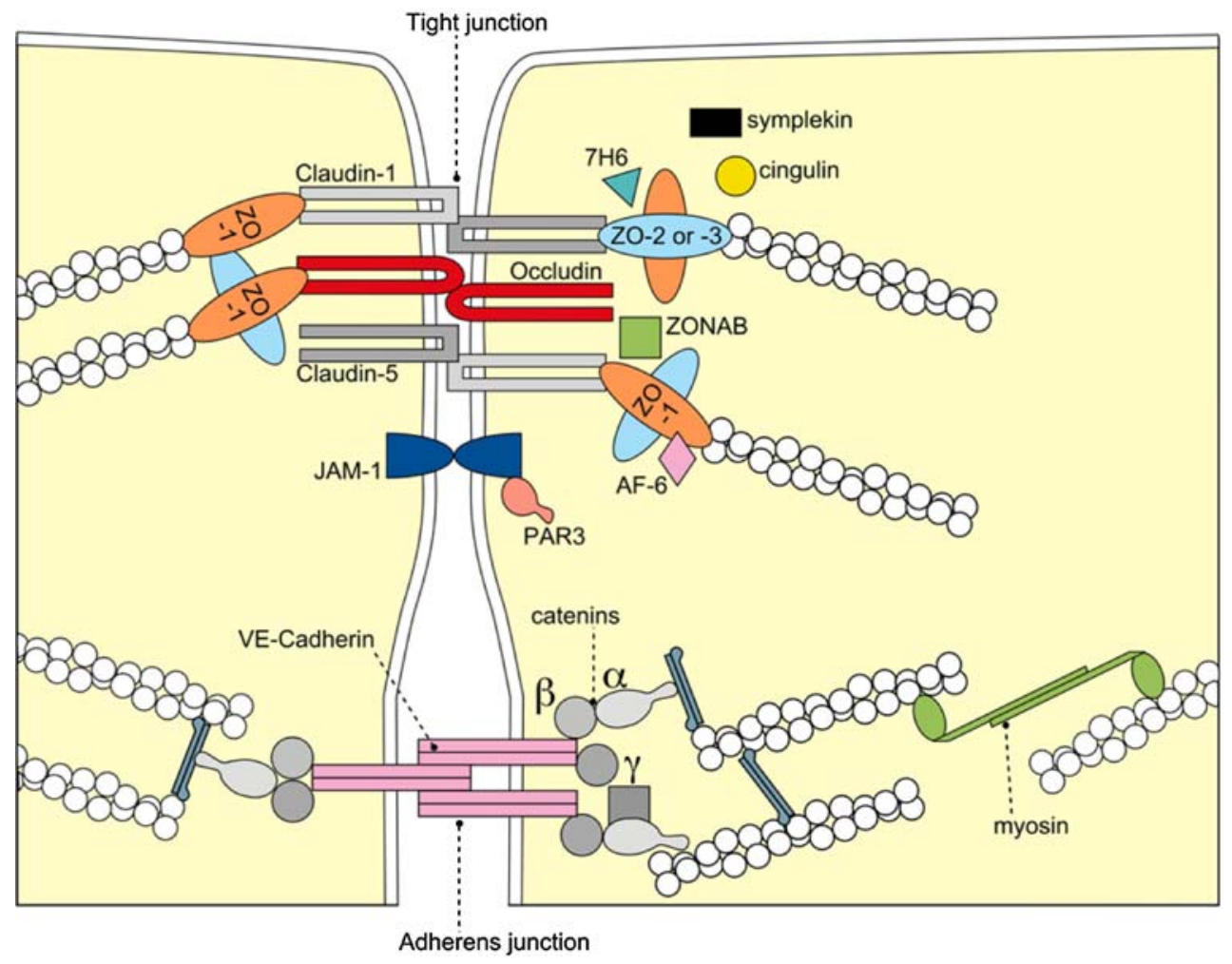

Fig. 1 Molecular composition of tight junctions. The transmembrane proteins occludin, the claudin(s) and junctional adhesion molecule-1 (JAM-1) constitute the barrier formed by TJs sealing the paracellular space. They appear to be interacting in a homophilic manner, and occludin seems to co-polymerase into claudin-based TJ strands. Claudins adhere with each other in a homotypic as well as a heterotypic manner. ZO-1, -2 , and -3 bind the cytoplasmic tail of occludin and link the $\mathrm{TJ}$ to the actin cytoskeleton. Proteins of the $\mathrm{ZO}$ family can shuttle to the nucleus to influence transcriptional processes in cellular proliferation and differentiation. The ZO-proteins have also been shown to interact with claudins and provide molecular scaffolds for TJ assembly. Cingulin is a $140 \mathrm{kDa}$ TJ plaque protein which assoicates with the actomyosin cytoskeleton. Its putative function is transduction

yielding differences in permeability barrier function between different tissues (Staehelin 1973). However, since a direct linear relationship between the complexity of the TJ strand network and the measured transepithelial electrical resistance (TER) could not unambiguousy be established for all cell types analysed, it was predicted that the strands might contain pores that fluctuate between open and closed conformations, suggesting that the TJ strands appear to be remarkably dynamic (Claude 1978).

\section{Occludin}

Recent identification of the TJ-specific integral membrane proteins forwarded our understanding of TJ molecular composition in mammals: occludin (ca. $60 \mathrm{kDa}$ ) was identified as the first integral membrane protein localised at TJs in chicken (Furuse et al. 1993) and then also in mammals of the mechanical force generated by the actomyosin cytoskeleton important for cellular differentiation. The Ras target AF-6 interacts with ZO-1 and serves as a. peripheral component of tight junctions in epithelial cells. Symplekin is a $126 \mathrm{kDa}$ protein that occurs and probably functions in the nucleus as well as in the TJ plaques. Tyrosine phosphorylated Par3 regulates tight junction assembly and promotes cellular polarity by intracellular signalling. Localization of $7 \mathrm{H} 6$ TJ-associated antigen along the cell border of vascular endothelial cells has been shown to correlate with paracellular barrier function. Additional proteins have been localised to the TJs but a function has presently not been assigned. Moreover diverse signaling proteins are detected at the apical junctional complex but they are not uniquely confined to the TJ

(Ando-Akatsuka et al. 1996). The occludin transmembrane domain spans the membrane four times with a short cytoplasmic N-terminus and an especially long corboxy-terminal cytoplasmic domain (Fig. 3a). Occludin localizes to the TJs, and its overexpression increases TER in mammalian epithelial cells (Balda et al. 1996). However, transfection of insect cells devoid of endogenous TJs with occludin cDNA surprisingly demonstrated that occludin is not by itself sufficient to form $\mathrm{TJ}$ strands but its expression merely produced focal homophilic adhesion sites (Furuse et al. 1996). Moreover, disruption of both occludin alleles in embryonic stem cells did not prevent the formation of an effective diffusion barrier and the polarisation of epithelial cells, as shown by freeze-fracture analysis and TER assessment (Saitou et al. 1998). It was thus concluded that occludin is not required for the formation of TJ strands. However, occludin appears to interact, directly or indirectly, with claudins and is recruited into the long strands formed by 


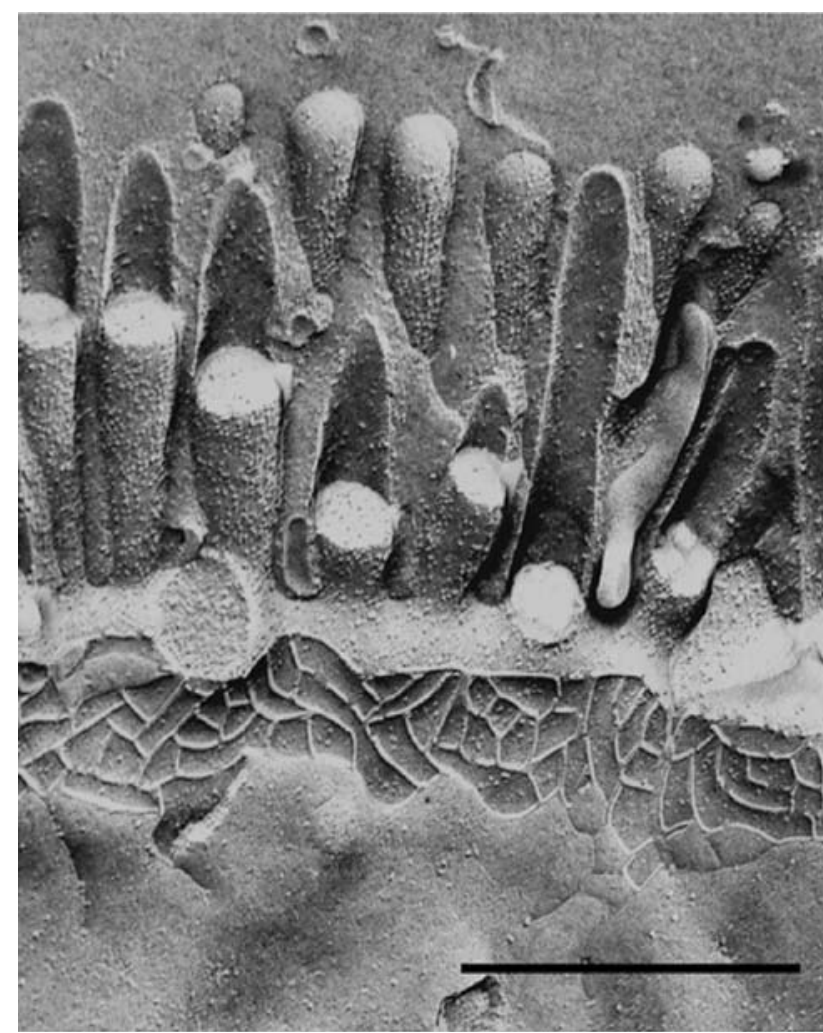

Fig. 2 Freeze-fracture image of the rat intestinal epithelium. The freeze fracture electron micrograph showns the apical brush border, the intramembraneous particle strands of the TJs and the lateral cell surface. The replica shows a continous network of TJ strands. Adapted from (Achler et al. 1989) with permission from D. Drenckhahn, Universität Würzburg. Bar $0.5 \mu \mathrm{m}$

coexpression of claudin-1 and claudin-2 (Furuse et al. 1998b, 1999). Balda et al. (1996) however reported that overexpression of both, wild type and $\mathrm{COOH}$-terminally truncated occludin overexpression in cultured MDCK epithelial cells induces not only a modest increase in TER but also significant increase in the flux of the non-charged compound FITC-dextran $4 \mathrm{kDa}$. Using freeze-fracture electron microscopy and immunocytochemistry, they were able to attribute this increase in paracellular permeability to an altered distribution and membrane topology between neighbouring cells.

\section{The claudins}

Searching for the proteins forming the structural backbone of the TJ strands, the Tsukita group re-examined the junctional fraction prepared from chicken liver and discovered the first members of the claudin family: two $22-\mathrm{kDa}$ proteins, claudin-1 and claudin-2 (Furuse et al. 1998a).

The claudins also have four transmembrane domains, but do not show any sequence similarity to occludin (Fig. 3b). So far, 24 members of the claudin family have been identified in different species. Claudins appear to be expressed in a tissue-specific manner; some claudins are expressed only in specific cell types, e.g. claudin-5 is expressed primarily by vascular endothelial cells or claudin-11 appears to be expressed solely in oligodendrocytes and Sertoli cells (Morita et al. 1999). Moreover, most cell types express more than two claudin isoforms conferring different size and charge selectivity qualities by the amino acid sequence of their extracellular loops, and the combination of those isoforms results in cell- or tissue-type specific barrier function by "heteropolymerisation" into the resulting TJ strands (see below). As demonstrated by immunogold electron microscopy, there is accumulating evidence now that the claudins do constitute the TJ strands as observed by freeze-fracture electron microscopy (Tsukita et al. 2001). Exogenous expression of claudins in fibroblasts devoid of endogenous TJs resulted in the formation of TJ strands.

Summarizing existing data, there is clear evidence that the claudins constitute the backbone of TJ strands, while occludin, which itself cannot reconstitute such TJ strands, seems to play a permeability regulating role by incorporating itself into the claudin-based strands, a process, the mechanism of which however is not yet understood. The function(s) of occludin thus still remain to be elucidated.

\section{Junction-associated adhesion molecules (JAMs)}

A third class of integral membrane proteins comprises members of the immunoglobulin superfamily (Fig. 3c), and can be subdivided into a group consisting of JAM proteins and a group consisting of CAR, CLMP, ESAM and JAM-4 (Ebnet 2008; Ebnet et al. 2004). To date, at least three JAM isoforms have been described, which are expressed differentially in epithelial and endothelial cells, but also in cells devoid of TJ strands like leukocytes (D'Atri and Citi 2002). Except for JAM-1, little is known about the role of these proteins in TJ assembly and function. JAM-1, formerly F11 receptor (Sobocka et al. 2000) (Fig. 3c), may be involved in immune cell transmigration or cell adhesion (Bazzoni et al. 2000) but has not been localized to the junction strands. A putative PDZ binding motif in the cytoplasmic domain of JAM-1 has been identified, which has been able to interact with PDZ domains of ZO-1, AF-6, PAR-3 and MUPP1 (D'Atri and Citi 2002; Itoh et al. 2001). Moreover, JAM-1 has been shown to interact with cingulin. Thus, even though JAM-1 is not part of the TJ strands, it may well be involved in the propagation of signal cascades resulting from homophilic and heterophilic adhesion. A role for JAM-1 in the complex process of adhesion and transmigration of monocytes through endothelial cells has been demonstrated (Martin-Padura et al. 1998). As another function 


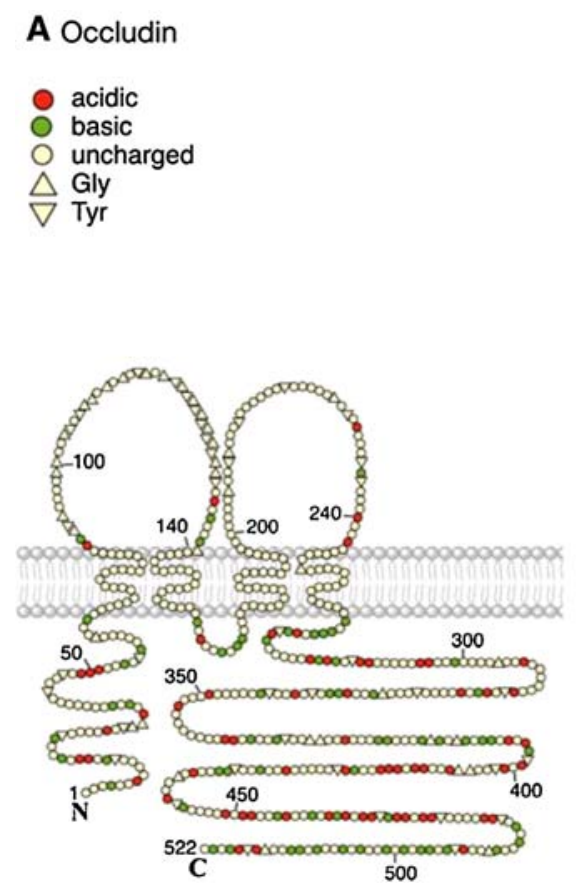

Fig. 3 Transmembrane proteins of the tight junction. a Murine occludin is a 521 amino acid protein. The first extracellular domain may be involved in cell-cell interaction containing a high tyrosine and glyine domain (triangles), acidic amino acids (orange-red), basic amino acids (green), neutral amino acids (cream). A second functional domain was assigned to the carboxy terminal 150 amino acids which appears to be responsible for the association of occludin with $\mathrm{ZO}-1$. The occludin amino acid sequence is highly conserved between species (Ando-Akatsuka et al. 1996). b Claudins are four transmembrane domain proteins, containing two extracellular and one intracellular loop and a $\mathrm{N}$ - and $\mathrm{C}$-terminal cytoplasmic domain. Claudins are a multigene family with so far 24 members identified in diverse species. In the first extracellular loop, claudins have a conserved common motif, GLWxxC(8-10aa)C (blue). Claudins further contain a PDZ-binding motif at the $\mathrm{C}$ terminus (orange) capable of bining to TJ plaque proteins like ZO-1. The claudins show a isotype-specific tissue expression pattern. c JAM-1 is an integral membrane protein expressed in endothelial and epithelial

for the JAM proteins, a role in the assembly of TJs and regulation of paracellular permeability could be deciphered by ectopic transfection experiments (Cohen et al. 2001). Interaction of JAM-1 with occludin, so far not determined whether direct or indirect in nature, has been shown (Liu et al. 2000).

\section{TJ plaque proteins and the coordination of signaling at the TJ}

In addition to their prime function as a regulated permeability barrier in the paracellular pathway and as fence in the plane of the membrane, TJs play a pivotal role in organizing such diverse processes as morphogenesis, cell polarity, cell proliferation, and differentiation, which require the coordination of signals impinging on and emanating from the cells. Its extracellular domain can dimerize and bind homophilically. The intracellular domain (and in particular a PDZ-binding motif) enable JAM-1 to interact with structural and signaling proteins. JAM-1 is localized at the tight junctions of epithelial and endothelial cells and is involved in the regulation of junctional integrity and permeability. The polypeptide sequence of 299 amino acids has the typical feature observed in a type I integral membrane protein. A putative signal peptide may be cleaved between Leu23 and Val24 (pink), leaving 215 residues in the extracellular domain of the mature protein. A stretch of 17 hydrophobic residues (Ile $239 \rightarrow$ Phe 255 ) presents a potential transmembrane region, and there are 45 residues in the cytoplasmic domain. The extracellular portion contains two domains with intrachain disulfide bonds typical of immunoglobulin-like loops of the V-type. Numerous PKC (blue) and Casein kinase II (yellow) phophorylation sites have been detected involved in platelet activation processes (Sobocka et al. 2000). Cys-43, -111, 146, -214 form dimer containing disulfide bridges and are labeled in black

plasma membrane. Mounting evidence suggests that the cytosolic TJ plaque is one of the sites in which such signaling is coordinated (Ebnet 2008; Gonzalez-Mariscal et al. 2003; Schneeberger and Lynch 2004). Since identification in 1986 of zonula occludens (ZO)-1 as the first TJ-associated protein (Stevenson et al. 1986), almost 30 additional proteins have been described associated with the cytoplasmic aspect of TJs (Schneeberger and Lynch 2004). They can be grouped into two major categories: The first are the peripherally associated scaffolding proteins like ZO-1 (ZO2, ZO-3, AF6, and cingulin) that appear to organize the transmembrane proteins and couple them to other cytoplasmic proteins and to actin microfilaments. The second are numerous "signaling" proteins (ZONAB, RhoA, RalA, and Raf-1) proposed to be involved in junction assembly, barrier regulation, gene transcription, and perhaps other, presently undefined pathways. 


\section{TJs as permeability barrier}

One of the key functions of tight epithelia is the creation of a diffusion barrier by tight control of the transcellular and paracellular pathways. This is acomplished by asymmetrical distribution of transporters and channels for the transcellular route, and on the other side by regulation of diffusion through the paracellular space via integral TJ proteins (Turner 2006). Hereby, certain claudins participate in the formation of ion-selective pores: available data suggest that TJs on the one hand are permeable to small noncharged solutes up to a size of $0.43-0.45 \mathrm{~nm}$ in radius as shown by the use of the membrane-impermeant polyethylene glycol as a tracer, but investigations also showed that pores within the TJs are capable of discriminating between ion charge and size, which both are additionally dependent on concentration and pH (Schneeberger and Lynch 2004; van Bree et al. 1988).

The two extracellular loops of occludin consist solely of uncharched amino acid side chains (Fig. 3a) represented mainly by an unusually high content of tyrosine and glycine (Furuse et al. 1993) so that a direct role for occludin in conferring charge selectivity is doubtful. However, occludin could increase electrical resistance by interaction with the extracellular domains of the differently charged residues of the different claudins (see below), since ablation of occludin is not without consequence despite the fact that the protein does not appear to be required for TJ strand formation. Occludin-null mice express a complex phenotype, which is, however, not manifested by structural or functional TJ abnormalities: in occludin $-/-$ mice, TJs were not affected morphologically, and electrophysiological barrier function of intestinal epithelium was normal. However, histopathological abnormalities were detected in several tissues, i.e., chronic inflammation and hyperplasia of the gastric epithelium, calcification in the brain, testicular atrophy, the loss of cytoplasmic granules in striated duct cells of the salivary gland as well as the thinning of the compact bone, pointing to complex functions of the occludin protein (Saitou et al. 2000).

\section{Role of claudin proteins in formation of a $\mathbf{T J}$ permeability barrier}

The lack of charged amino acid residues within the extracellular loops of occludin segregates occludin from the candidates contributing directly to the formation of ionselective pores. The different claudins whose extracellular loops span a wide range of $\mathrm{p} K_{i}$ on the contrary appear to be excellent candidates to mediate ion selectivity in TJ permeability (Fig. 3b). Major insight into the distinct charge selectivity of the claudins came from the work of Furuse et al. (2001), who could relate the different levels of resistance between MDCK I cells (TER $>10,000 \Omega \mathrm{cm}^{2}$ ) and MDCK II cells (TER $<200 \Omega \mathrm{cm}^{2}$ ) to a differential claudin isoform expression, while MDCK I cells express claudin-1 and -4 but not claudin-2, MDCK II cells additionally express claudin-2, which seems to mediate higher ion permeability by pore formation/inducing strand breaks. Notably, transfection of the tight MDCK I with claudin-2 cDNA resulted in 20-fold decline in TER but not in the number of TJ strands.

A wide range of further transfection and mutagenesis experiments introducing or ablating different claudins has been performed to date, and been partially helpful to elucidate the conductance conferring properties of the resulting pores (Matter and Balda 2003b). These informative observations must however be viewed with some caution because transfection and site-directed mutagenesis may lead to more than a change in net charge as for example an altered molecular conformation, or altogether the introduction of an unusual claudin protein could lead to disturbance of strand organisation within native strands. By the construction of chimera, Colegio et al. (2003) were moreover able to attribute ion selectivity of the claudins to distinct stretches within the primary amino acid sequence of the extracellular loops leading to alterations in TER and charge selectivity in transfection experiments. Taken together, available data strongly suggest a key role for the extracellular loops of the diverse claudins in the formation of ion selective pores within the TJ strands.

\section{Role of occludin in formation of a TJ permeability barrier}

The role of occludin in TJs and a putative contribution to building up the TJ's ion selectivity (the ion pores) is unclear; it has been demonstrated that overexpression of occludin in MDCK cells reduces ion permeability but in the same time was shown to increase the transepithelial flux of the uncharged compound mannitol (Balda et al. 1996). Further observations then implicated that occludin may be a target for receptor-initiated signalling involving the Rho family of GTPases, and that by an additional not-yet-understood mechanism, occludin phosphorylation may regulate $\mathrm{TJ}$ permeability independently of cytoskeletal activity (Hirase et al. 2001).

Some indirect evidence for a role of occludin in strengthening barrier properties arose from heterologous expression studies: when expressed in L-fibroblasts that lack endogenous cadherin-based adherens junctions and ZO-1, little adhesiveness was measured (Kubota et al. 1999). However, when overexpressed in fibroblasts, which do have well developed ZO-1-containing adherens-like junctions (NRK- 
fibroblasts), increased $\mathrm{Ca}^{2+}$-independent adhesion was observed, indicating that when interacting with ZO-1, occludin mediates adhesive functions (Van Itallie and Anderson 1997). Addition of neutralizing peptides of the peptide sequence of the second extracellular loop elicited competitive interference with cell-cell-adhesion in a dose dependent manner, implicating that this loop directly participates in adhesive interaction (Wong and Gumbiner 1997).

Relating epithelial malignancy to the loss of cell-celladhesion, it was demonstrated that overexpression of oncogenic Raf 1 in rat salivary gland epithelial cells (Pa4-Raf1) disrupts TJs and induces an oncogenic phenotype by downregulating the expression of occludin (Wang et al. 2005). Raf1-mediated transformation of Pa4-Raf1 cells was subsequently shown to induce transcriptional downregulation of occludin and forced re-expression of occludin rescued the polarized phenotype of epithelial cells (Wang et al. 2007). Interestingly, forced expression of an occludin mutant lacking the second extracellular loop did not rescue the epithelial phenotype in vitro nor did it prevent tumor growth in vivo. These results demonstrate that the TJ protein occludin has a potent inhibitory effect on the Raf1mediated tumorigenesis, and the second loop of occludin appears to be required for suppression of Raf1-induced tumor growth, potentially by mediating cell-cell-adhesion as presented above contributing to contact inhibition of cell division.

\section{TJs and human disease}

Modulation of barrier function by cytokines

Many cytokines have been shown to influence epithelial and endothelial TJ function and the actin cytoskeleton both in vivo and in vitro. To name the most prominent, the interleukins IL-0, IL-1, IL-3, IL-4, as well as tumor necrosis factor alpha $(\mathrm{TNF} \alpha)$ and interferon gamma (IFN $\gamma)$ could be demonstrated to influence TJ barrier function in epithelia and endothelia (Ahdieh et al. 2001; Oshima et al. 2001; Youakim and Ahdieh 1999). This review will emphasise the influence of a few selected cytokines on TJ structure/ function and its adjoining actin cytoskeleton in diseases like inflammatory bowel disease and inflammatory disease of the CNS (Table 1).

\section{Inflammatory bowel disease: Crohn's disease}

Crohn's disease ranks among the chronic inflammatory bowel diseases (IBD) with diarrhoea as a leading symptom. This is chiefly attributed to epithelial barrier dysfunction,

Table 1 Modulation of TJ barrier function in human disease

\begin{tabular}{|c|c|c|}
\hline Classification & Tight junction protein affected & Reference \\
\hline \multicolumn{3}{|l|}{ Cancer } \\
\hline Breast cancer: invasive ductal cancer & Claudin-1, ZO-1 & Itoh and Bissell (2003), detailed here \\
\hline Prostate cancer: prostatic adenocarcinomas & Claudins- $1,-3,-4$ and claudin- 7 & Sheehan et al. (2007) \\
\hline Thyroid neoplasma, follicular adenoma & Occludin and claudin-1, -4 and -7 & Tzelepi et al. (2007) \\
\hline $\begin{array}{l}\text { Gastroesophageal reflux disease: } \\
\text { Barrett's esophagus (dysplasia) }\end{array}$ & Claudin-18 & Jovov et al. (2007) \\
\hline Lung cancer: Basaloid squamous carcinoma & $\begin{array}{l}\text { Ultrastructural junctional } \\
\text { dedifferentiation }\end{array}$ & Gilcrease and Guzman-Paz (1998) \\
\hline \multicolumn{3}{|l|}{ Inflammation } \\
\hline Inflammatory bowel disease: Morbus Crohn & Claudins-2,-3, -5 , and $-8, \mathrm{ZO}-1$ & Zeissig et al. (2007), detailed here \\
\hline Collagenous collitis & Occludin, claudin-2 and -4 & Burgel et al. (2002) \\
\hline Multiple sclerosis & Occludin, claudin-5 & Förster et al. (2007), detailed here \\
\hline \multicolumn{3}{|l|}{ Hereditary diseases } \\
\hline Hereditäry deafness & Claudin-14 & Ben-Yosef et al. (2003), detailed here \\
\hline Familial hypomagnesemia & Claudin-16 & Simon et al. (1999), detailed here \\
\hline cystic fibrosis & Occludin, claudin-1, -4, JAM, ZO-1 & Coyne et al. (2002) \\
\hline \multicolumn{3}{|l|}{ Vision loss } \\
\hline Diabetic eye disease: diabetic retinopathy & Occludin, ZO-1 & Felinski and Antonetti (2005), detailed here \\
\hline \multicolumn{3}{|l|}{ Viral infection } \\
\hline Reoviral infection (hydrocephalus, encephalitis) & JAM-1 & Forrest et al. (2003) \\
\hline \multicolumn{3}{|l|}{ Bacterial toxins } \\
\hline Clostridium perfringens enterotoxin & Claudin- 3 and -4 & McClane (2001), detailed here \\
\hline
\end{tabular}


leading to an increased loss of solutes in the form of "leakflux diarrhoea". Notably, the integrity of the intestinal barrier is not only impaired in patients with Crohn's disease but also many first-degree relatives of Crohn's disease patients present with increased intestinal permeability in the absence of clinical symptoms (Hollander 1993; Peeters et al. 1997; Yacyshyn and Meddings 1995). From this observation it was concluded that barrier dysfunction in Crohn's disease precedes the inflammatory process in contrast to many other inflammatory diseases, probably arising from genetic defects or driven by environmental factors like intestinal luminal antigens or bacterial toxins.

The epithelial barrier in the intestine is established by a single layer of epithelial cells. However, barrier dysfunction alone does not to seem be sufficient to cause Crohn's disease, since unaffected relatives of patients with Crohn's disease comparably present increased permeability, but do not show the abnormal mucosal inflammatory response reported of patients with Crohn's disease (Weber and Turner 2007). In healthy individuals, the intestinal mucosal barrier is organised through tight junction strands connecting the adjacent epithelial cells (Weber and Turner 2007). These TJs seal the paracellular space and an intact intestinal mucosa. TJ permeability is rate limiting for epithelial permeability and defects thereof are an established source for intestinal barrier defects as observed in Crohn's disease. The basic understanding of TJ function we developed is that they form an ion-selective and size-selective paracellular gate whose permeability varies throughout the gastrointestinal tract (see above). According to this, it is not surprising that the pattern of claudin isoforms expressed varies alongside the gastrointestinal tract (Nusrat et al. 2000). Recent studies now show that the expression pattern of characteristic claudins is altered in Crohn's disease (Weber and Turner 2007) with a concomitant effect on the integrity of TJ strands: Zeissig et al. (2007) showed by freeze-fracture electron microscopy that the overall number of $\mathrm{TJ}$ strands sealing the epithelial layer is reduced while concomitantly an increased number of strand breaks was noted in tissue from patiens with Crohn's disease (Zeissig et al. 2007). The expression of 12 claudin isoforms in the intestinal epithelium was investigated in healthy individuals and patients with Crohn's disease, leading to the insight that the expression of the claudins $-3,-5$, and -8 was decreased in active disease. On the contrary, expression of barrier-reducing claudin- 2 was increased in histological samples from patients, which was particularly observed in the crypt epithelium. This altered pattern of claudin isoform expression was thus concluded to be partly responsible for the observed mophological and functional disruption of TJs. However, claudin isoform expression patterns were unaltered in patients with inactive Crohn's disease, rendering this observed change in expression patterns rather a consequence than a cause of active disease.

It is has been acknowledged for a long time that chronic inflammation in Crohn's disease is associated with the overproduction of proinflammatory cytokines. Searching for the nature of these pro-inflammatory mediators effecting the TJ disruption and dysfunction, investigators (Conyers et al. 1990; Heller et al. 2005; Prasad et al. 2005) had identified IL-13, IFN $\gamma$ and TNF $\alpha$ as factors in patient's serum lowering resistance and opening TJs. However, differential effects of the different cytokines crititical to IBD pathogenis have been reported from studies in cell culture models, indicating that the mechanisms by which IFN $\gamma$ and TNF $\alpha$ inrease paracelluar permeability differ from those used by IL-13 (Prasad et al. 2005). IFN $\gamma$ and TNF $\alpha$ exposure of model cell lines led to a reduction in claudin-2 expression, while IL-13 exposure induced increased claudin-2 expression. Those observed discrepancies, which might be based on the source of epithelial cell lines, the experimental design or the doses of cytokines applied are the focus of current investigation. Other lines of research are concentrated on gaining more information on the source of proinflammatory cytokines in IBD and the mode how those cytokines may work together to modify claudin expression pattern, either in vitro or in vivo (Weber and Turner 2007).

At the cell biological level, recent investigation demonstrated that IFN $\gamma$ exposure promoted the endocytosis of occludin, JAM-1 and claudin-1 into early and recycling endosomes (Bruewer et al. 2005), an effect which appears to be mediated by RhoA/Rho kinase, which further induced a myosin II-dependent formation of vacuoles in the apical cell moiety (Utech et al. 2005).

At the gene expression level, other research groups could demonstrate that TNF $\alpha$ induced an increase in Caco-2 TJ permeability mediated by activation of the pro-inflammatory transcription factor $\mathrm{NF} \kappa \mathrm{B}$. NF $\kappa \mathrm{B}$ action leads to a downregulation of specifically ZO-1 gene expression and a redistribution of ZO-1 protein away from the intercellular junctions (Ma et al. 2004). A comparable effect could be described in the nonintestinal model epithelial cell line, MDCK, and in the blood brain barrier model cell line cEND, where also disruption of TJs following exposure of epithelial and endothelial cells to TNF $\alpha$ could be demonstrated (Förster et al. 2007; Poritz et al. 2004).

\section{Blood-brain barrier compromise in neuroinflammation-multiple sclerosis}

Homeostasis of the central nervous system (CNS) microenvironment is essential for its normal function. It is maintained by the blood-brain barrier (BBB) which regulates the transport of molecules from blood into brain and backwards. The function of this highly specialised barrier is to 
(1) protect the brain from blood-borne substances and (2) to provide nutrient supply to the brain parenchyme by specialised transport systems (Rubin and Staddon 1999).

The main structures responsible for this barrier property are the TJ. TJ are strongly developed in endothelial cells of the BBB but only moderately formed between endothelial cells of the peripheral vasculature: leaky blood vessels in the body allow many molecules to cross through to tissue, but the tight construction of the vessels in the CNS guards against brain entry, leading to high electrical resistance in the range of $1,500-2,000 \Omega \mathrm{cm}^{2}$, depending on the species investigated. In BBB-forming brain capillary endothelial cells (BCECs) the TJ proteins occludin and claudin-5, claudin-3, claudin-1 and claudin-12 were demonstrated by immunofluorescence and western blot analysis (Förster et al. 2007; Wolburg and Lippoldt 2002).

Under physiological conditions, brain microvascular endothelial cells form a barrier limiting the extravasation of cells of the immune system like monocytes, lymphocytes and other leukocytes. It has been shown in this context that leukocytes can transmigrate to the BBB without net changes in vascular permeability and cell-cell contacts (Cramer 1992). However, increased leukocyte migration as in multiple sclerosis (MS) has been reported to lead to a reorganisation of the actin cytoskeleton and breakdown of the TJ proteins occludin and ZO-1 (Couraud 1998; Förster et al. 2007). MS is characterised as a chronic and progressive CNS disease with a remitting-relapsing profile. In the course of the disease, both demyelination and microvascular inflammation have been described as central pathophysiological insults. From an animal model for MS, experimental allergic encephalomyelitis (EAE) (Korner and Sedgwick 1996), the inflammatory cytokines TNF $\alpha$ and IL-1 have been delineated to be the key mediators inducing alterations in BBB permeability. Clinically matching data have been collected from MS patients, who show an elevation in $\mathrm{TNF} \alpha$ and/or IL-1 in cerebrospinal fluid (CSF) (Weber and Rieckmann 1995). Cytokine-promoted opening of the BBB has been shown to occur due to degradation and decreased synthesis of TJ proteins (Chang and Werb 2001; Harkness et al. 2000; Silwedel and Förster 2006; Yang et al. 2006), resulting in compromised junctional integrity. Particularly, the TJ proteins occludin and ZO-1 have been shown to be negatively affected by the presence of these pro-inflammatory cytokines. Searching for the mechanism of TJ protein degradation, consecutive studies showed, that in many neuroinflammatory conditions, including MS, the matrix metalloproteinases (MMP) play an important role in disrupting the BBB. Amongst these, it has been demonstrated that selectively, MMP-9 (gelatinase B) is increased in CSF levels in MS patients. Tissue inhibitors of metalloproteinases (TIMPs) form complexes with either activated
MMPs or with their pro-forms after their secretion, thus regulating MMP activity under physiological conditions (Brew et al. 2000; Yong et al. 2001). Levels of TIMP-1 are however reduced in MS patients relative to control patients, suggesting an imbalance in MMP-9/TIMP-1 ratios in MS (Avolio et al. 2005). MMP-9-mediated opening of the BBB then allows amplification of the inflammation, as demonstrated by radioisotopes (Kermode et al. 1990). Looking for therapeutical agents restoring the unbalaced MMP-9/ TIMP-1 ratios in MS, Förster et al. (2007) showed that glucocorticoid treatment reduces the levels of MMP-9 markedly in a cell culture model of the BBB, an effect which was shown to be based on glucocorticoid-mediated transcriptional activation of the TIMP-1 gene. This study further demonstrated that the administration of the glucocorticoids dexamethasone and hydrocortisone preserved the functional integrity of the TJs and adherens junctions under proinflammatory conditions, chiefly by maintaining the levels of the TJ components occludin, claudin-1, claudin-12, ZO1 and VE-cadherin, while dexamethasone effects on claudin-5 were negligible (Blecharz et al. 2008; Förster et al. 2007).

Another study demonstrated differential susceptibility of cerebral and cerebellar endothelial cell lines to BBB breakdown in response to inflammatory stimuli (Silwedel and Förster 2006): increased fragility of the cerebellar $\mathrm{BBB}$ had been reported, as the typical caudal to rostral lesion development of MS and EAE with a preference of the cerebellum indicates (Cross et al. 1993; Juhler et al. 1984; Namer et al. 1993). Matching those studies, the authors could demonstrate a faster and more pronounced increase in permeability in the cerebellar BBB manifested by reduced TER and reduced TJ protein expression using the cerebellar BBB model cell line cerebEND (Silwedel and Förster 2006). The stronger effects of TNF $\alpha$ on endothelial cells of the cerebellum as compared the the cerebrum could be explained on the cellular level, where the TJ protein levels of claudin-5 and occludin were shown to be differently affected in cerebellar and cerebral microvascular endothelial cells: effects on occludin were more pronounced in cerebellar endothelial cells, while cerebral endothelial cells of the BBB showed a stronger decrease in claudin-5. Since it was shown that the main protein buiding up the barrier appears to be occludin, while claudin-5 protein, which is also well detectable in non-BBB endothelial cells, does not seem to influence barrier properties to the same extent (Foerster et al. 2002, 2005, 2006; Wolburg and Lippoldt 2002). One may speculate that the lower overall occludin contents of endothelial cells of the cerebellar BBB compared to the cerebral BBB can partly explain the greater sensitivity of the cerebellar BBB to inflammatory stimuli. 
Hereditäry diseases

\section{Hereditäry deafness: nonsyndromic recessive deafness DFNB29}

The cochlea of the inner ear is divided into two compartments of different ionic composition. Hereby, the perilymph of the scala vestibuli and scala tympani is high in $\mathrm{Na}^{+}$but low in $\mathrm{K}^{+}$concentration, while the endolymph of the scala media resembles the intracellular ionic composition, being high in $\mathrm{K}^{+}$but low in $\mathrm{Na}^{+}$(Ferrary and Sterkers 1998). This ion gradient leads to the establishment of an 80-100 $\mathrm{mV}$ endocochlear potential, necessary for the depolarisation of sensory hair cells, enhancing the sensitivity of mechano-activated channels at the top of stereocilia (Hudspeth 1989).

Besides, hereditary defects in the gap junction proteins connexin-26 and connexin-43 (Sabag et al. 2005) an association between tight junctions and hearing loss was established. The importance of claudin-14 expression in the cochlea was demonstrated by the identification of two different CLDN14 mutations that cause nonsyndromic recessive deafness DFNB29 in two large consanguineous Pakistani families (Wilcox et al. 2001). By in situ hybridization and immunofluorescence labeling mouse claudin-14 expression in the sensory epithelium of the organ of Corti was observed. By the generation and characterisation of claudin-14 knockout mice as a model for autosomal-recessive deafness DFNB29 it was revealed that deafness occurred due to death of outer hair cells. Searching for the factors that promoted increased death of outer hair cells, morphology of the TJs of claudin-14 knockout mice was evaluated. It was demonstrated that $\mathrm{TJ}$ strands between supporting cells and between outer hair cells and supporting cells in the organ of Corti are still present and appear morphologically normal in freeze fracture replicas. The analysed TJ strands which are composed of multiple claudins were thus concluded to have rather a functional than an ultrastructural defect (Ben-Yosef et al. 2003). Following the reasoning that claudins create charge-selective channels, Ben-Yosef characterised the electrophysiologic properties of claudin 14 by ectopically expressing it in MDCK cells, which revealed a strong discrimination of transfected monolayers against $\mathrm{Na}^{+}$and $\mathrm{K}^{+}$ions. Ben-Yosuf and coworkers thus concluded that the absence of claudin 14 from TJs in the organ of Corti might lead to elevated $\mathrm{K}^{+}$ concentration in the space of Nuel, which is normally filled with the $\mathrm{K}^{+}$-poor cortilymph and increased death of outer hair cells. Long-term exposure of the basolateral membranes of outer hair cells to high $\mathrm{K}^{+}$concentrations had been shown to be toxic and eventually to lead to cell death before (Zenner 1986).
By the identification of two claudin-14 missense mutations that were unable to form TJs after ectopic expression of CLDN14 in L mouse fibroblastes, Wattenhofer et al. (2005) were then able to prove that the basis for the development of deafness is incorrect recruitment and TJ strand formation in cells expressing mutated CLDN14.

\section{Familial hypomagnesemia with hypercalciuria and nephrocalcinosis (FHHNC)}

Inherited and acquired defects in epithelial membrane transport are responsible for many human diseases. In the kidney, tubular claudins play a role in extracellular or paracellular permeability. In this context, it has been shown that mutations in claudin-16 (Paracellin-1) impair the function of TJs in the paracellular resorption of $\mathrm{Mg}^{2+}$ and $\mathrm{Ca}^{2+}$ but not of monovalent cations (Simon et al. 1999), probably founding the molecular basis for the development of familial hypomagnesemia with hypercalciuria and nephrocalcinosis (FHHNC), an autosomal recessive renal tubular disorder. In FHHNC patients, the impaired tubular reabsorption of $\mathrm{Mg}^{2+}$ and $\mathrm{Ca}^{2+}$ in the thick ascending limb of the loop of Henle with an eventual progression can lead to end-stage renal disease (Lee et al. 2006). Functional tubular reabsorbtion mechanisms are vitally important, since a normal adult absorbs only $200 \mathrm{mg} \mathrm{Ca}^{2+}$ from the diet each day, but loses $8,000 \mathrm{mg}$ to filtration across the glomerulus. To achieve normal calcium balance, the majority of the filtered load must be reabsorbed by the tubule, to approximately $90 \%$, or $7,000 \mathrm{mg} /$ day and this occurs mainly via the paracellular pathway driven by a lumen positive potential across the tubular wall.

The structural backbone of the paracellular pathway must provide for the significant substrate selectivity and functional heterogeneity between nephron segments and thus also plays a pathophysiologic role in renal diseases. Clinically, the symptoms and gradual kidney damage caused by FHHNC cannot be alleviated by intravenous or oral supplementation with $\mathrm{Mg}^{2+}$, and kidney transplantation is often the only option at later stages of the disease.

Recent studies (Simon et al. 1999) have reported that FHHNC is caused by mutations in a gene, which encodes the TJ protein, paracellin-1. Paracellin-1 (PLCN-1) belongs to the claudin family (claudin-16) that allows the paracellular transport of $\mathrm{Mg}^{2+}$ and $\mathrm{Ca}^{2+}$. As a member of the claudin family of TJ proteins claudin-16 exhibits four transmembrane spans with two extracellular loops and both termini located in the cytoplasm. To date, more than 20 distinct mutations have been identified, which affect either the trafficking of PLCN-1/claudin-16, or its permeability properties (Kausalya et al. 2006). 
Interestingly, FHHNC patients do not exhibit the salt wasting or metabolic alkalosis that is found in Bartter's syndrome (Wong and Goodenough 1999). Based on these findings, it is tempting to hypothesize that PCLN-1 might form a $\mathrm{Mg}^{2+}$ - and $\mathrm{Ca}^{2+}$-conducting pore. It is therefore likely that PCLN-1 selectively mediates the barrier to divalent but not monovalent cations. Thus, not only can the paracellular barrier discriminate between charged and uncharged solutes, but it may also exhibit an even higher level of specificity distinguishing charge and ionic radius and size of the hydrate shell.

As to molecular investigations based on the use of diverse cell culture models for kidney epithelial cells, there is some discrepancy between results obtained upon overexpression of PLCN-1 in two different kidney epithelial cell lines used. In the canine MDCK cell line, another group found PCLN-1 to decrease $\mathrm{Na}^{+}$permeability, to decrease TER and to enhance transepithelial $\mathrm{Mg}^{2+}$ transport (Ikari et al. 2006). Another recent study performed in the porcine proximal tubule LLC-PK1 cells suggests that paracellin-1 functions to modulate paracellular conductance and not transcellular transport. They hypothesise that PLCN-1 mediates mostly paracellular $\mathrm{Na}^{+}$permeation to build up the positive lumen potential and that this lumen-positive potential would be the driving force for the reabsorption of $\mathrm{Mg}^{2+}$ (Hou et al. 2005).

As described for other molecules relevant to $\mathrm{Mg}^{2+}$ homeostasis such as ACDP2, (ancient conserved domain protein), a divalent metal transporter, or the $\mathrm{Mg}^{2+}$ transporter MagT1 (Wong and Goodenough 1999), the human PLCN-1 promoter appears to be responsive to external $\mathrm{Mg}^{2+}$ concentrations, since the renal epithelial cell specific PLCN-1 gene expression was shown to positively correlate with the amount of $\mathrm{Mg}^{2+}$ offered in the growth medium (Efrati et al. 2005).

Further, mutations in PLCN-1 can affect claudin-16 protein targeting at the TJs (Kausalya et al. 2006). The mutation T233R for example prevents interaction of claudin-16 with ZO-1 and results in lysosomal targeting of claudin-16 instead. Protein kinase A (PKA) mediates phosphorylation of claudin-16 at Ser217, failure of which equally leads to dissociation of claudin-16 from ZO-1 and its translocation into the lysosomes (Ikari et al. 2006). In conclusion, although the mechanism of PLCN-1/claudin-16-mediated $\mathrm{Mg}^{2+}$ and $\mathrm{Ca}^{2+}$ reabsorbtion is not yet fully understood, it is clear that these claudins play a crucial role in this process.

Recently, Konrad et al. (2006) additionally unravelled a role for claudin-19 in the development of FHHNC. They had clinically characterized one Swiss and eight Spanish/ Hispanic families affected with severe hypomagnesemia due to renal wasting, nephrocalcinosis, and progressive renal failure but had to recognize that the individuals did not have any mutations in CLDN16. They showed that the renal phenotype of the affected patients was virtually undistinguishable from that of patients who presented with FHHNC with proven CLDN16 mutations. However, the affected individuals in these families also have severe visual impairment, characterized by macular colobomata, significant myopia, and horizontal nystagmus (Konrad et al. 2006). Konrad et al. were able to map a new locus for recessive renal magnesium loss on chromosome $1 \mathrm{p} 34.2$ and identified mutations in CLDN19, yet another member of the claudin family in patients affected with FHHNC and additionally, with severe ocular abnormalities. CLDN19, which encodes the tight-junction protein claudin-19 was demonstrated to be highy expressed in renal tubules and the retina. In an effort to understand the mechanisms underlying the roles of the two claudins in mediating paracellular ion reabsorption in the kidney, Goodenough and co workers (Hou et al. 2008) showed using pig kidney epithelial cells, that CLDN19 functioned as a $\mathrm{Cl}(-)$ blocker, whereas CLDN16 functioned as a $\mathrm{Na}(+)$ channel. Mutant forms of CLDN19 were shown to be associated with FHHNC since they were unable to block $\mathrm{Cl}(-)$ permeation. Coexpression experiments further elucidated that CLDN16 interacts with CLDN19 and that their association confers cation selectivity, suggesting a role for mutant forms of CLDN16 and CLDN19 in the development of FHHNC.

Vascular system

\section{Diabetic retinopathy}

The barrier between the vascular lumen and neural layers in the retina and the brain parenchyme maintains a characteristic microenvironment and is essential for proper neuronal function. This blood-retinal barrier (BRB) consists of two anatomical entities: an inner BRB formed by junctions between endothelial cells of the retinal capillaries, and an outer BRB composed of TJs between retinal pigment epithelial cells. Clinical evidence from fluorescein angiography has demonstrated that the inner BRB appears to be the primary site of vascular leakage leading to macular edema.

The BRB is built up and maintained by TJ complexes that make up the blood vessels of the microvasculature (Mitic and Anderson 1998). The principal proteins found in the retinal endothelial TJs are occludin and claudin-5 (Dejana et al. 2001). Loss of the BRB integrity and vascular permeability leading to macular edema (Vitale et al. 1995) characterise diabetic retinopathy. Macular edema in turn is thought to be directly responsible for vision loss in diabetic retinopathy (Felinski and Antonetti 2005). Vascular endothelial growth factor (VEGF) is thought to be chiefly responsible for this increase in BRB permeability, albeit other permeabilizing factors like histamin or the cytokines IL-1 and TNF $\alpha$ have also been implicated (Felinski and 
Antonetti 2005). Levels of VEGF, originally identified as an angiongenic factor serving as a mitogen for vascular endothelial cells have been recently correlated with increased vascular permeability (Felinski and Antonetti 2005), compatible with increased VEGF levels detected in the vitreous of diabetic patients for decades. There is enough evidence to show that diabetes and VEGF induce retinal vascular permeability by altering TJ complexes, evidenced for instance by the decrease in occludin content in the retinas of diabetic rats (Felinski and Antonetti 2005). In cultured primary bovine retinal endothelial cells, this observation was mirrored by the observation of decreased occludin contents after VEGF administration (Antonetti et al. 1998). Follow-up investigation underlined this and showed down-regulation of occludin in retinal endothelial cells in culture after VEGF stimulation. VEGF further activates PKC, which leads to increased occludin and ZO-1 phosphorylation (Harhaj et al. 2006). Phosphorylation of occludin and ZO-1 likely contribute to dysregulated endothelial paracellular permeability (Abbott et al. 2006). Regulation of PKC activity and TJ protein modifications may thus have therapeutic implications for treatment of diabetic retinopathy.

Recent investigation has further revealed that alterations of the BRB may involve the active proteolytic breakdown of the endothelial cell TJs by MMPs as also evidenced in the case of MS (compare above) (Leppert et al. 2001). Specifically, elevated levels of MMP-9 have been seen when retinal endothelial cells were exposed to high glucose conditions as a cell culture model of diabetes, leading to proteloytic degradation of specifically the TJ protein occludin followed by disruption of the overall $\mathrm{TJ}$ complex (Giebel et al. 2005), rendering the regulation of MMP secretion and activity another therapeutical target in diabetic retinopathy.

\section{Multiple sclerosis}

See above.

Tight junction alterations in cancer

\section{Decreased expression of claudin-1 correlates with malignant potential in breast cancer}

Changes in TJ function have been shown to be an early and key aspect in cancer metastasis (Ehler et al. 2001). Recent studies showed a role for claudin- 1 in invasion and metastasis in mammary glandular differentiation (Förster et al. 2002) and carcinogenesis (Morohashi et al. 2007).

Interestingly, there is an absence or significant loss of claudin-1 expression in several established breast cancer cell lines. Claudin-1 expression in primary human mam- mary epithelial cells, in contrast to low or undetectable levels of expression in a number of breast tumors and breast cancer cell lines, points to claudin-1 as a possible tumor-suppressor gene. In sections from surgically resected breast specimens, a significant loss of claudin-1 protein in breast cancer cells could be shown by immunohistochemistry (Tokes et al. 2005). This finding suggests that claudin-1 may play a role in invasion and metastasis. The expression profile of claudin-1 in non-malignant versus tumor-derived cells has made this gene an interesting candidate for involvement in tumorigenesis, namely by acting as a suppressor of mammary epithelial proliferation.

In order to evaluate the CLDN-1 gene in sporadic and hereditary breast cancer, Krämer et al. (2000) characterized its genomic organization and screened the four coding exons for somatic mutations in 96 sporadic breast carcinomas and for germline mutations in 93 breast cancer patients with a strong family history of breast cancer. In addition, they compared the $5^{\prime}$-upstream sequences of the human and murine CLDN1 genes to identify putative promoter sequences involved in down-regulation of the CLDN1 gene under malignant conditions and examined both the promoter and coding regions of the human gene in various breast cancer cell lines showing decreased claudin-1 expression. However, neither in sporadic or hereditary breast cancers, nor in breast cancer cell lines they found evidence for a role of aberrant claudin- 1 in breast tumorigenesis and concluded that other regulatory or epigenetic factors could be involved in the downregulation of the CLDN1 gene during breast cancer development.

A correlation between TJ abnormalities and neoplasia can be supported by several observations: alterations in the number, appearance, and permeability of TJs have been demonstrated in various cancer types (Cochand-Priollet et al. 1998; Soler et al. 1999; Swift et al. 1983) and in premalignant mammary epithelial cells (Förster et al. 2002). At the molecular level, the Drosophila lethal(1) discs-large1 gene (dlg) product, which localises to TJ-related insect septate junctions has been shown to regulate epithelial cell proliferation. Genetic loss of dlg leads to a neoplastic overgrowth phenotype (Woods and Bryant 1991). The loss of expression of claudin-1 itself has been demonstrated in several mammary carcinoma cell lines (Swisshelm et al. 1999). The expression of the TJ plaque protein ZO-1 has been shown to be reduced in breast carcinomas or breast cancer cells (Hoover et al. 1998). These findings support the hypothesis that claudin-1 might be involved in the development of breast cancer and possibly in other epithelial tumors too.

The molecular pathways leading toward the loss of claudin-1 expression however, remain to be explained. 


\section{Bacterial toxins}

\section{Clostridium perfringens enterotoxin}

Food poisoning by Clostridium perfringens enterotoxin (CPE) leads to diarrhea symptoms classified as "C. perfringens type A food poisoning and antibiotic-associated diarrhea". The enterotoxin protein has been elucidated to intrude the cells by interacting with epithelial TJ, including certain claudins. Toxin-induced cytolytic pore-formation is a prerequisite for this and involves residues in the N-terminal half of CPE protein, while residues near the $\mathrm{C}$-terminus are required for binding to claudins. In detail, the single $35 \mathrm{kDa}$ CPE polypeptide first causes cellular damage by altering plasma membrane permeability by the formation of an approximately $155 \mathrm{kDa}$ CPE-containing pore complex necessary for the subsequent interaction with TJ proteins via its C-terminal receptor-binding region (McClane 2001). CPE was then perceived to affect TJ structure and function in a way that permeability properties of the epithelial layer are altered leading to diarrhea (McClane 2001).

Further investigation has determined the isoforms of claudins targeted by CPE. Sonoda et al. (1999) were able to show that the $\mathrm{COOH}$-terminal half fragment of CPE (CCPE) bound effectively to claudin-3 and claudin-4 in MDCK I cells expressing the claudins-1, $-2,-3$ and -4 . They were further able to show that in the presence of C-CPE, reconstituted TJ strands gradually disintegrated and disappeared from their cell surface in C3L cells.

As a consequence, because diverse claudins are overexpressed on some human cancers, the toxin became interesting for targeting chemotherapy in the manner of a Trojan horse (Long et al. 2001; Michl et al. 2001).

Recently, van Itallie et al. (2007) aimed to solve the structure of the CPE claudin-binding domain to advance its therapeutic applications. The structure was shown to be a nine-strand beta sandwich with previously unappreciated similarity to the receptor-binding domains of several other toxins of spore-forming bacteria, giving strong evidence for the presence of a common ancestor for several receptorbinding domains of bacterial toxins (Van Itallie et al. 2007). The very recent elucidation of the structure of a 14$\mathrm{kDa}$ fragment containing residues 194 to the native $\mathrm{COOH}$ terminus at position 319 by $\mathrm{X}$-ray diffraction to a resolution below $2 \AA$ showed that the structure is a nine-strand $\beta$ sandwich with previously unappreciated similarity to the receptor-binding domains of several other toxins of sporeforming bacteria, i.e., the collagen-binding domain of $\mathrm{ColG}$ from Clostridium histolyticum and the large Cry family of toxins (including Cry4Ba) of Bacillus thuringiensis (Van Itallie et al. 2008). The authors speculate that the claudin-4 binding site is on a large surface loop between strands $\beta 8$ and $\beta 9$ or includes both of these strands. They further were able to clarify that the sequence crystallized binds to purified human claudin-4 with a 1:1 stoichiometry. The binding affinity was determined to be in the submicromolar range similar to that observed for binding of native toxin to cells (Van Itallie et al. 2008). These results could now provide a structural framework to advance therapeutic applications of the toxin.

\section{Conclusion and perspectives}

The discovery of the existence of occludin- and claudinbased TJs constituting a permeability barrier in epithelial and endothelial cells has paved the way for the elucidation of the molecular background of diverse human diseases the pathogenesis of which had been unclear before. It became clear that the presence of TJs is indispensable for tissue compartmentalisation and cellular homeostasis. Disturbances in TJ function are reflected in many diseases, but on the other hand, awareness of their involvement has facilitated therapy enormously. For instance, antiinflammatory or antimetastatic drugs could be developed based on their ability to repair broken barrier function. These strategies have become indispensable in the treatment of disease like MS, inflammatory bowel disease or diabetic retinopathy. Following the strategy of pathogenic agents, which use TJ proteins as a docking station to invade cells, even strategies for drug delivery techniques could be implemented. Future attempts will have to address the role of occludin and the exact contribution of the diverse claudins to the formation of ion selective pores, which are still open questions. A more thorough understanding will greatly facilitate diagnosis and the development of specific treatment regimens for diseases originating from impaired TJ function.

Acknowledgments This work was supported by grant SFB688/ TPA5 from Deutsche Forschungsgemeinschaft DFG to CF. The author is especially thankful toDetlev Drenckhahn for constructive suggestions and critical reading of the manuscript. The author is grateful to Kinga Blecharz for editing expertise and Malgorzata Burek for efficient and pleasant help in collection of material.

\section{References}

Abbott NJ, Ronnback L, Hansson E (2006) Astrocyte-endothelial interactions at the blood-brain barrier. Review. Nat Rev Neurosci $7: 41-53$

Achler C, Filmer D, Merte C, Drenckhahn D (1989) Role of microtubules in polarized delivery of apical membrane proteins to the brush border of the intestinal epithelium. J Cell Biol 109:179-189

Ahdieh M, Vandenbos T, Youakim A (2001) Lung epithelial barrier function and wound healing are decreased by IL-4 and IL-13 and enhanced by IFN-gamma. Am J Physiol Cell Physiol 281:C2029$\mathrm{C} 2038$

Ando-Akatsuka Y, Saitou M, Hirase T, Kishi M, Sakakibara A, Itoh M, Yonemura S, Furuse M, Tsukita S (1996) Interspecies diversity of 
the occludin sequence: cDNA cloning of human, mouse, dog, and rat-kangaroo homologues. J Cell Biol 133:43-47

Antonetti DA, Barber AJ, Khin S, Lieth E, Tarbell JM, Gardner TW (1998) Vascular permeability in experimental diabetes is associated with reduced endothelial occludin content: vascular endothelial growth factor decreases occludin in retinal endothelial cells. Penn State Retina Research Group. Diabetes 47:1953-1959

Avolio C, Filippi M, Tortorella C, Rocca MA, Ruggieri M, Agosta F, Tomassini V, Pozzilli C, Stecchi S, Giaquinto P, Livrea P, Trojano M (2005) Serum MMP-9/TIMP-1 and MMP-2/TIMP-2 ratios in multiple sclerosis: relationships with different magnetic resonance imaging measures of disease activity during IFN-beta-1a treatment. Mult Scler 11:441-446

Balda MS, Whitney JA, Flores C, Gonzalez S, Cereijido M, Matter K (1996) Functional dissociation of paracellular permeability and transepithelial electrical resistance and disruption of the apicalbasolateral intramembrane diffusion barrier by expression of a mutant tight junction membrane protein. J Cell Biol 134:10311049

Bazzoni G, Martinez-Estrada OM, Orsenigo F, Cordenonsi M, Citi S, Dejana E (2000) Interaction of junctional adhesion molecule with the tight junction components $\mathrm{ZO}-1$, cingulin, and occludin. J Biol Chem 275:20520-20526

Ben-Yosef T, Belyantseva IA, Saunders TL, Hughes ED, Kawamoto K, Van Itallie CM, Beyer LA, Halsey K, Gardner DJ, Wilcox ER, Rasmussen J, Anderson JM, Dolan DF, Forge A, Raphael Y, Camper SA, Friedman TB (2003) Claudin 14 knockout mice, a model for autosomal recessive deafness DFNB29, are deaf due to cochlear hair cell degeneration. Hum mol genet 12:2049-2061

Blecharz K, Drenckhahn D, Förster C (2008) Glucocorticoids increase VE-cadherin expression and cause cytoskeletal re-arrangements in murine brain endothelial cEND cells. J Cereb Blood Flow Metab 1-11. doi:10.1038/jcbfm.2008.2

Brew K-, Dinakarpandian D, Nagase H (2000) Tissue inhibitors of metalloproteinases: evolution, structure and function. Biochem Biophys Acta 1477:267-283

Bruewer M, Utech M, Ivanov AI, Hopkins AM, Parkos CA, Nusrat A (2005) Interferon-gamma induces internalization of epithelial tight junction proteins via a macropinocytosis-like process. Faseb J 19:923-933

Burgel N, Bojarski C, Mankertz J, Zeitz M, Fromm M, Schulzke JD (2002) Mechanisms of diarrhea in collagenous colitis. Gastroenterology 123:433-443

Chang C, Werb Z (2001) The many faces of metalloproteases: cell growth, invasion, angiogenesis and metastasis. Trends Cell Biol 11:S37-S43

Claude P (1978) Morphological factors influencing transepithelial permeability: a model for the resistance of the zonula occludens. J Membr Biol 39:219-232

Cochand-Priollet B, Raison D, Molinie V, Guillausseau PJ, Wassef M, Bouchaud C (1998) Altered gap and tight junctions in human thyroid oncocytic tumors: a study of 8 cases by freeze-fracture. Ultrastruct pathol 22:413-420

Cohen CJ, Shieh JT, Pickles RJ, Okegawa T, Hsieh JT, Bergelson JM (2001) The coxsackievirus and adenovirus receptor is a transmembrane component of the tight junction. Proc Natl Acad Sci USA 98:15191-15196

Colegio OR, Van Itallie C, Rahner C, Anderson JM (2003) Claudin extracellular domains determine paracellular charge selectivity and resistance but not tight junction fibril architecture. Am J Physiol Cell Physiol 284:C1346-C1354

Conyers G, Milks L, Conklyn M, Showell H, Cramer E (1990) A factor in serum lowers resistance and opens tight junctions of MDCK cells. Am J Physiol 259:C577-C585

Couraud PO (1998) Infiltration of inflammatory cells through brain endothelium. Pathol Biol 46:176-180
Coyne CB, Vanhook MK, Gambling TM, Carson JL, Boucher RC, Johnson LG (2002) Regulation of airway tight junctions by proinflammatory cytokines. Mol Biol Cell 13:3218-3234

Cramer EB (1992) The ability of leukocytes to cross the tight junctions. In: Cerejido M (ed) Tight junctions. CRC Press, Boca Raton, pp 321-336

Cross AH, O'Mara T, Raine CS (1993) Chronologic localization of myelin-reactive cells in the lesions of relapsing EAE: implications for the study of multiple sclerosis. Neurology 43:1028-1033

D'Atri F, Citi S (2002) Molecular complexity of vertebrate tight junctions. Mol Membr Biol 19:103-112

Dejana E, Spagnuolo R, Bazzoni G (2001) Interendothelial junctions and their role in the control of angiogenesis, vascular permeability and leukocyte transmigration. Thromb Haemost 86:308-315

Ebnet K (2008) Organization of multiprotein complexes at cell-cell junctions. This issue

Ebnet K, Suzuki A, Ohno S, Vestweber D (2004) Junctional adhesion molecules (JAMs): more molecules with dual functions? J Cell Sci 117:19-29

Efrati E, Arsentiev-Rozenfeld J, Zelikovic I (2005) The human paracellin-1 gene (hPCLN-1): renal epithelial cell-specific expression and regulation. Am J Physiol Renal Physiol 288:F272-F283

Ehler E, Horowits R, Zuppinger C, Price RL, Perriard E, Leu M, Caroni P, Sussman M, Eppenberger HM, Perriard J-C (2001) Alterations at the intercalated disk associated with the absence of muscle LIM protein. J Cell Biol 153:763-772

Farquhar MG, Palade GE (1963) Junctional complexes in various epithelia. J Cell Biol 17:375-412

Felinski EA, Antonetti DA (2005) Glucocorticoid regulation of endothelial cell tight junction gene expression: novel treatments for diabetic retinopathy. Curr Eye Res 30:949-957

Ferrary E, Sterkers O (1998) Mechanisms of endolymph secretion. Kidney Int Suppl 65:S98-S103

Förster C, Waschke J, Burek M, Leers J, Drenckhahn D (2006) Glucocorticoid effects on microvascular endothelial barrier permeability are brain specific. J Physiol 573(Pt 2):413-425

Forrest JC, Campbell JA, Schelling P, Stehle T, Dermody TS (2003) Structure-function analysis of reovirus binding to junctional adhesion molecule 1. Implications for the mechanism of reovirus attachment. J Biol Chem 278:48434-48444

Förster C, Kietz S, Kahles T, Drenckhahn D (2007) Dexamethasone induces the expression of metalloproteinase inhibitor TIMP-1 in the murine cerebral vascular endothelial cell line cEND. J Physiol 580.3:937-949

Förster C, Makelä S, Becker D, Hultenby K, Warner M, Gustafsson J$\AA ̊$ (2002) Involvement of Estrogen receptor beta in terminal differentiation of mammary epithelium. Proc Natl Acad Sci USA 99:15578-15583

Förster C, Silwedel C, Golenhofen N, Burek M, Kietz S, Mankertz J, Drenckhahn D (2005) Occludin as direct target for glucocorticoid-induced improvement of blood brain-barrier properties in a murine in vitro system. J Physiol 565(Pt 2):475-486

Furuse M, Fujimoto K, Sato N, Hirase T, Tsukita S (1996) Overexpression of occludin, a tight junction-associated integral membrane protein, induces the formation of intracellular multilamellar bodies bearing tight junction-like structures. J Cell Sci 109(Pt 2):429-435

Furuse M, Fujita K, Hiiragi T, Fujimoto K, Tsukita S (1998a) Claudin1 and -2 : novel integral membrane proteins localizing at tight junctions with no sequence similarity to occludin. J Cell Biol 141:1539-1550

Furuse M, Furuse K, Sasaki H, Tsukita S (2001) Conversion of zonulae occludentes from tight to leaky strand type by introducing claudin2 into Madin-Darby canine kidney I cells. J Cell Biol 153:263-272

Furuse M, Hirase T, Itoh M, Nagafuchi A, Yonemura S, Tsukita S (1993) Occludin: a novel integral membrane protein localizing at tight junctions. J Cell Biol 123:1777-1788 
Furuse M, Sasaki H, Fujimoto K, Tsukita S (1998b) A single gene product, claudin- 1 or -2 , reconstitutes tight junction strands and recruits occludin in fibroblasts. J Cell Biol 143:391-401

Furuse M, Sasaki H, Tsukita S (1999) Manner of interaction of heterogeneous claudin species within and between tight junction strands. J Cell Biol 147:891-903

Giebel SJ, Menicucci G, McGuire PG, Das A (2005) Matrix metalloproteinases in early diabetic retinopathy and their role in alteration of the blood-retinal barrier. Lab Invest 85:597-607

Gilcrease MZ, Guzman-Paz M (1998) Fine-needle aspiration of basaloid squamous carcinoma: a case report with review of differential diagnostic considerations. Diagn Cytopathol 19:210-215

Gonzalez-Mariscal L, Betanzos A, Nava P, Jaramillo BE (2003) Tight junction proteins. Prog Biophys Mol Biol 81:1-44

Harhaj NS, Felinski EA, Wolpert EB, Sundstrom JM, Gardner TW, Antonetti DA (2006) VEGF activation of protein kinase C stimulates occludin phosphorylation and contributes to endothelial permeability. Invest Ophthalmol Vis Sci 47:5106-5115

Harkness KA, Adamson P, Sussman JD, Davies-Jones GAB, Greenwood J, Woodroofe MN (2000) Dexamethasone regulation of matrix metalloprteinase expression in CNS vascular endothelium. Brain 13:698-709

Heller F, Florian P, Bojarski C, Richter J, Christ M, Hillenbrand B, Mankertz J, Gitter AH, Burgel N, Fromm M, Zeitz M, Fuss I, Strober W, Schulzke JD (2005) Interleukin-13 is the key effector Th2 cytokine in ulcerative colitis that affects epithelial tight junctions, apoptosis, and cell restitution. Gastroenterology 129:550 564

Hirase T, Kawashima S, Wong EY, Ueyama T, Rikitake Y, Tsukita S, Yokoyama M, Staddon JM (2001) Regulation of tight junction permeability and occludin phosphorylation by Rhoa-p160ROCKdependent and -independent mechanisms. J Biol Chem 276:10423-10431

Hollander D (1993) Permeability in Crohn's disease: altered barrier functions in healthy relatives? Gastroenterology 104:1848-1851

Hoover KB, Liao SY, Bryant PJ (1998) Loss of the tight junction MAGUK ZO-1 in breast cancer: relationship to glandular differentiation and loss of heterozygosity. Am J Pathol 153:1767-1773

Hou J, Paul DL, Goodenough DA (2005) Paracellin-1 and the modulation of ion selectivity of tight junctions. J Cell Sci 118:5109-5118

Hou J, Renigunta A, Konrad M, Gomes AS, Schneeberger EE, Paul DL, Waldegger S, Goodenough DA (2008) Claudin-16 and claudin-19 interact and form a cation-selective tight junction complex. J Clin Invest 118:619-628

Hudspeth AJ (1989) How the ear's works work. Nature 341:397-404

Ikari A, Matsumoto S, Harada H, Takagi K, Hayashi H, Suzuki Y, Degawa M, Miwa M (2006) Phosphorylation of paracellin-1 at Ser217 by protein kinase A is essential for localization in tight junctions. J Cell Sci 119:1781-1789

Itoh M, Bissell MJ (2003) The organization of tight junctions in epithelia: implications for mammary gland biology and breast tumorigenesis. J Mammary Gland Biol Neoplasia 8:449-462

Itoh M, Sasaki H, Furuse M, Ozaki H, Kita T, Tsukita S (2001) Junctional adhesion molecule (JAM) binds to PAR-3: a possible mechanism for the recruitment of PAR-3 to tight junctions. J Cell Biol 154:491-497

Jovov B, Van Itallie CM, Shaheen NJ, Carson JL, Gambling TM, Anderson JM, Orlando RC (2007) Claudin-18: a dominant tight junction protein in Barrett's esophagus and likely contributor to its acid resistance. Am J Physiol 293:G1106-G1113

Juhler M, Barry DI, Offner H, Konat G, Klinken L, Paulson OB (1984) Blood-brain and blood-spinal cord barrier permeability during the course of experimental allergic encephalomyelitis in the rat. Brain Res 302:347-355

Kausalya PJ, Amasheh S, Gunzel D, Wurps H, Muller D, Fromm M, Hunziker W (2006) Disease-associated mutations affect intracel- lular traffic and paracellular $\mathrm{Mg} 2+$ transport function of Claudin16. J Clin Invest 116:878-891

Kermode AG, Thompson AJ, Tofts P, MacMans DG, Kendall BE, Kingsley DPao (1990) Breakdown of the blood-brain barrier precedes symptoms and other MRI signs of new lesions in multiple sclerosis. Pathogenetic and clinical implications. Brain 113:1477-1489

Konrad M, Schaller A, Seelow D, Pandey AV, Waldegger S, Lesslauer A, Vitzthum H, Suzuki Y, Luk JM, Becker C, Schlingmann KP, Schmid M, Rodriguez-Soriano J, Ariceta G, Cano F, Enriquez R, Juppner H, Bakkaloglu SA, Hediger MA, Gallati S, Neuhauss SC, Nurnberg P, Weber S (2006) Mutations in the tight-junction gene claudin 19 (CLDN19) are associated with renal magnesium wasting, renal failure, and severe ocular involvement. Am J Hum Genet 79:949-957

Korner H, Sedgwick JD (1996) Tumour necrosis factor and lymphotoxin: molecular aspects and role in tissue-specific autoimmunity. Immunol Cell Biol 74:465-472

Kramer F, White K, Kubbies M, Swisshelm K, Weber BH (2000) Genomic organization of claudin-1 and its assessment in hereditary and sporadic breast cancer. Hum Genet 107:249-256

Kubota K, Furuse M, Sasaki H, Sonoda N, Fujita K, Nagafuchi A, Tsukita S (1999) Ca(2+)-independent cell-adhesion activity of claudins, a family of integral membrane proteins localized at tight junctions. Curr Biol 9:1035-1038

Lee DB, Huang E, Ward HJ (2006) Tight junction biology and kidney dysfunction. Am J Physiol Renal Physiol 290:F20-F34

Leppert D, Lindberg RLP, Kappos L, Leib S (2001) Matrix metalloproteinases: multifunctional effectors of inflammation in multile sclerosis and bacterial meningitis. Brain Res Rev 36:249-257

Liu Y, Nusrat A, Schnell FJ, Reaves TA, Walsh S, Pochet M, Parkos CA (2000) Human junction adhesion molecule regulates tight junction resealing in epithelia. J Cell Sci 113 (Pt 13):2363-2374

Long H, Crean CD, Lee WH, Cummings OW, Gabig TG (2001) Expression of Clostridium perfringens enterotoxin receptors claudin-3 and claudin- 4 in prostate cancer epithelium. Cancer Res 61:7878-7881

Ma TY, Iwamoto GK, Hoa NT, Akotia V, Pedram A, Boivin MA, Said HM (2004) TNF-alpha-induced increase in intestinal epithelial tight junction permeability requires NF-kappa B activation. Am J Physiol 286:G367-G376

Martin-Padura I, Lostaglio S, Schneemann M, Williams L, Romano M, Fruscella P, Panzeri C, Stoppacciaro A, Ruco L, Villa A, Simmons D, Dejana E (1998) Junctional adhesion molecule, a novel member of the immunoglobulin superfamily that distributes at intercellular junctions and modulates monocyte transmigration. J Cell Biol 142:117-127

Matter K, Balda MS (2003a) Functional analysis of tight junctions. Methods 30:228-234

Matter K, Balda MS (2003b) Holey barrier: claudins and the regulation of brain endothelial permeability. J Cell Biol 161:459-460

McClane BA (2001) The complex interactions between Clostridium perfringens enterotoxin and epithelial tight junctions. Toxicon 39:1781-1791

Michl P, Buchholz M, Rolke M, Kunsch S, Lohr M, McClane B, Tsukita S, Leder G, Adler G, Gress TM (2001) Claudin-4: a new target for pancreatic cancer treatment using Clostridium perfringens enterotoxin. Gastroenterology 121:678-684

Mitic LL, Anderson JM (1998) Molecular architecture of tight junctions. Annu Rev Physiol 60:121-142

Morita K, Sasaki H, Fujimoto K, Furuse M, Tsukita S (1999) Claudin11 OSP-based tight junctions of myelin sheaths in brain and sertoli cells in testis. J Cell Biol 145:579-588

Morohashi S, Kusumi T, Sato F, Odagiri H, Chiba H, Yoshihara S, Hakamada K, Sasaki M, Kijima H (2007) Decreased expression of claudin- 1 correlates with recurrence status in breast cancer. Int J Mol Med 20:139-143 
Namer IJ, Steibel J, Poulet P, Armspach JP, Mohr M, Mauss Y, Chambron J (1993) Blood-brain barrier breakdown in MBP-specific T cell induced experimental allergic encephalomyelitis. A quantitative in vivo MRI study. Brain 116 (Pt 1):147-159

Nusrat A, Parkos CA, Verkade P, Foley CS, Liang TW, Innis-Whitehouse W, Eastburn KK, Madara JL (2000) Tight junctions are membrane microdomains. J Cell Sci 113 (Pt 10):1771-1781

Oshima T, Laroux FS, Coe LL, Morise Z, Kawachi S, Bauer P, Grisham MB, Specian RD, Carter P, Jennings S, Granger DN, Joh T, Alexander JS (2001) Interferon-gamma and interleukin-10 reciprocally regulate endothelial junction integrity and barrier function. Microvasc Res 61:130-143

Peeters M, Geypens B, Claus D, Nevens H, Ghoos Y, Verbeke G, Baert F, Vermeire S, Vlietinck R, Rutgeerts P (1997) Clustering of increased small intestinal permeability in families with Crohn's disease. Gastroenterology 113:802-807

Poritz LS, Garver KI, Tilberg AF, Koltun WA (2004) Tumor necrosis factor alpha disrupts tight junction assembly. J Surg Res 116:14-18

Prasad S, Mingrino R, Kaukinen K, Hayes KL, Powell RM, MacDonald TT, Collins JE (2005) Inflammatory processes have differential effects on claudins 2, 3 and 4 in colonic epithelial cells. Lab Invest 85:1139-1162

Rubin LL, Staddon JM (1999) The cell biology of the blood-brain barrier. Annu Rev Neurosci 22:11-28

Sabag AD, Dagan O, Avraham KB (2005) Connexins in hearing loss: a comprehensive overview. J Basic Clin Physiol Pharmacol 16:101-116

Saitou M, Fujimoto K, Doi Y, Itoh M, Fujimoto T, Furuse M, Takano H, Noda T, Tsukita S (1998) Occludin-deficient embryonic stem cells can differentiate into polarized epithelial cells bearing tight junctions. J Cell Biol 141:397-408

Saitou M, Furuse M, Sasaki H, Schulzke JD, Fromm M, Takano H, Noda T, Tsukita S (2000) Complex phenotype of mice lacking occludin, a component of tight junction strands. Mol Biol Cell 11:4131-4142

Schneeberger EE, Lynch RD (2004) The tight junction: a multifunctional complex. Am J Physiol Cell Physiol 286:C1213-C1228

Sheehan GM, Kallakury BV, Sheehan CE, Fisher HA, Kaufman RP Jr, Ross JS (2007) Loss of claudins- 1 and -7 and expression of claudins-3 and -4 correlate with prognostic variables in prostatic adenocarcinomas. Hum Pathol 38:564-569

Silwedel C, Förster C (2006) Differential susceptibility of cerebral and cerebellar murine brain microvascular endothelial cells to loss of barrier properties in response to inflammatory stimuli. J Neuroimmunol 179:37-45

Simon DB, Lu Y, Choate KA, Velazquez H, Al-Sabban E, Praga M, Casari G, Bettinelli A, Colussi G, Rodriguez-Soriano J, McCredie D, Milford D, Sanjad S, Lifton RP (1999) Paracellin-1, a renal tight junction protein required for paracellular $\mathrm{Mg} 2+$ resorption. Science 285:103-106

Sobocka MB, Sobocki T, Banerjee P, Weiss C, Rushbrook JI, Norin AJ, Hartwig J, Salifu MO, Markell MS, Babinska A, Ehrlich YH, Kornecki E (2000) Cloning of the human platelet F11 receptor: a cell adhesion molecule member of the immunoglobulin superfamily involved in platelet aggregation. Blood 95:2600-2609

Soler AP, Miller RD, Laughlin KV, Carp NZ, Klurfeld DM, Mullin JM (1999) Increased tight junctional permeability is associated with the development of colon cancer. Carcinogenesis 20:1425-1431

Sonoda N, Furuse M, Sasaki H, Yonemura S, Katahira J, Horiguchi Y, Tsukita S (1999) Clostridium perfringens enterotoxin fragment removes specific claudins from tight junction strands: Evidence for direct involvement of claudins in tight junction barrier. J Cell Biol 147:195-204

Staehelin LA (1973) Further observations on the fine structure of freeze-cleaved tight junctions. J Cell Sci 13:763-786
Stevenson BR, Siliciano JD, Mooseker MS, Goodenough DA (1986) Identification of ZO-1: a high molecular weight polypeptide associated with the tight junction (zonula occludens) in a variety of epithelia. J Cell Biol 103:755-766

Swift JG, Mukherjee TM, Rowland R (1983) Intercellular junctions in hepatocellular carcinoma. J Submicrosc Cytol 15:799-810

Swisshelm K, Machl A, Planitzer S, Robertson R, Kubbies M, Hosier S (1999) SEMP1, a senescence-associated cDNA isolated from human mammary epithelial cells, is a member of an epithelial membrane protein superfamily. Gene 226:285-295

Tokes AM, Kulka J, Paku S, Szik A, Paska C, Novak PK, Szilak L, Kiss A, Bogi K, Schaff Z (2005) Claudin-1, -3 and -4 proteins and mRNA expression in benign and malignant breast lesions: a research study. Breast Cancer Res 7:R296-R305

Tsukita S, Furuse M (1999) Occludin and claudins in tight-junction strands: leading or supporting players? Trends Cell Biol 9:268273

Tsukita S, Furuse M, Itoh M (2001) Multifunctional strands in tight junctions. Nat Rev Mol Cell Biol 2:285-293

Turner JR (2006) Molecular basis of epithelial barrier regulation: from basic mechanisms to clinical application. Am J Pathol 169:19011909

Tzelepi VN, Tsamandas AC, Vlotinou HD, Vagianos CE, Scopa CD (2008) Tight junctions in thyroid carcinogenesis: diverse expression of claudin-1, claudin-4, claudin-7 and occludin in thyroid neoplasms. Mod Pathol 21:22-30

Utech M, Ivanov AI, Samarin SN, Bruewer M, Turner JR, Mrsny RJ, Parkos CA, Nusrat A (2005) Mechanism of IFN-gamma-induced endocytosis of tight junction proteins: myosin II-dependent vacuolarization of the apical plasma membrane. Mol Biol Cell 16:5040-5052

van Bree JB, de Boer AG, Danhof M, Ginsel LA, Breimer DD (1988) Characterization of an in vitro blood-brain barrier: effects of molecular size and lipophilicity on cerebrovascular endothelial transport rates of drugs. J Pharmacol Exp Ther 247:1233-1239

Van Itallie CM, Anderson JM (1997) Occludin confers adhesiveness when expressed in fibroblasts. J Cell Sci 110(Pt 9):1113-1121

Van Itallie CM, Betts L, Smedley JG 3rd, McClane BA, Anderson JM (2008) Structure of the claudin-binding domain of clostridia perfringens enterotoxin. J Biol Chem 283:268-274

Van Itallie CM, Betts L, Smedley JG 3rd, McClane BA, Anderson JM (2008) Structure of the Claudin-binding Domain of Clostridium perfringens Enterotoxin. J Biol Chem 283:268-274

Vitale S, Maguire MG, Murphy RP, Hiner CJ, Rourke L, Sackett C, Patz A (1995) Clinically significant macular edema in type I diabetes. Incidence and risk factors. Ophthalmology 102:1170-1176

Wang Z, Mandell KJ, Parkos CA, Mrsny RJ, Nusrat A (2005) The second loop of occludin is required for suppression of Raf1-induced tumor growth. Oncogene 24:4412-4420

Wang Z, Wade P, Mandell KJ, Akyildiz A, Parkos CA, Mrsny RJ, Nusrat A (2007) Raf 1 represses expression of the tight junction protein occludin via activation of the zinc-finger transcription factor slug. Oncogene 26:1222-1230

Wattenhofer M, Reymond A, Falciola V, Charollais A, Caille D, Borel C, Lyle R, Estivill X, Petersen MB, Meda P, Antonarakis SE (2005) Different mechanisms preclude mutant CLDN14 proteins from forming tight junctions in vitro. Hum Mutat 25:543-549

Weber CR, Turner JR (2007) Inflammatory bowel disease: is it really just another break in the wall? Gut 56:6-8

Weber F, Rieckmann P (1995) Pathogenesis and therapy of multiple sclerosis. The role of cytokines. Nervenarzt 66:150-155

Wilcox ER, Burton QL, Naz S, Riazuddin S, Smith TN, Ploplis B, Belyantseva I, Ben-Yosef T, Liburd NA, Morell RJ, Kachar B, Wu DK, Griffith AJ, Riazuddin S, Friedman TB (2001) Mutations in the gene encoding tight junction claudin-14 cause autosomal recessive deafness DFNB29. Cell 104:165-172 
Wolburg H, Lippoldt A (2002) Tight junctions of the blood-brain barrier: development, composition and regulation. Vascul Pharmacol 38:323-337

Wolburg H, Liebner S, Lippoldt A (2003) Freeze-fracture studies of cerebral endothelial tight junctions. Methods Mol Med 89:51-66

Wong V, Goodenough DA (1999) Paracellular channels! Science 285:62

Wong V, Gumbiner BM (1997) A synthetic peptide corresponding to the extracellular domain of occludin perturbs the tight junction permeability barrier. J Cell Biol 136:399-409

Woods DF, Bryant PJ (1991) The discs-large tumor suppressor gene of Drosophila encodes a guanylate kinase homolog localized at septate junctions. Cell 66:451-464

Yacyshyn BR, Meddings JB (1995) CD45RO expression on circulating CD19+ B cells in Crohn's disease correlates with intestinal permeability. Gastroenterology 108:132-137

Yang Y, Estrada EY, Thompson JF, Liu W, Rosenberg GA (2007) Matrix metalloproteinase-mediated disruption of tight junction proteins in cerebral vessels is reversed by synthetic matrix metalloproteinase inhibitor in focal ischemia in rat. J Cereb Blood Flow Metab 27:697-709

Yong VW, Power C, Forsyth P, Edwards DR (2001) Metalloproteinases in biology and pathology of the nervous system. Nat Rev Neurosci 2:502-511

Youakim A, Ahdieh M (1999) Interferon-gamma decreases barrier function in T84 cells by reducing $\mathrm{ZO}-1$ levels and disrupting apical actin. Am J Physiol 276:G1279-G1288

Zahraoui A, Louvard D, Galli T (2000) Tight junction, a platform for trafficking and signaling protein complexes. J Cell Biol 151:F31F36

Zeissig S, Burgel N, Gunzel D, Richter J, Mankertz J, Wahnschaffe U, Kroesen AJ, Zeitz M, Fromm M, Schulzke JD (2007) Changes in expression and distribution of claudin 2, 5 and 8 lead to discontinuous tight junctions and barrier dysfunction in active Crohn's disease. Gut 56:61-72

Zenner HP (1986) $\mathrm{K}^{+}$-induced motility and depolarization of cochlear hair cells. Direct evidence for a new pathophysiological mechanism in Meniere's disease. Arch Otorhinolaryngol 243:108-111 